\title{
Short communication: Variation of total immunoglobulin G and $\beta$-lactoglobulin concentrations in colostrum and milk from Canadian Holsteins classified as high, average, or low immune responders
}

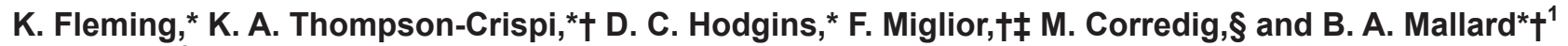 \\ *Department of Pathobiology, and \\ †Centre for Genetic Improvement of Livestock, University of Guelph, Guelph, Ontario, N1G 2W1, Canada \\ ¥Canadian Dairy Network, Guelph, Ontario, N1K 1E5, Canada \\ $\S$ Department of Food Science, University of Guelph, Guelph, Ontario, N1G 2W1, Canada
}

\section{ABSTRACT}

The objective of this study was to evaluate IgG and $\beta$-lactoglobulin ( $\beta$-LG) concentrations in colostrum and milk of Canadian Holsteins $(\mathrm{n}=108)$ classified as high $(\mathrm{H})$, average $(\mathrm{A})$, or low (L) for antibody-mediated (AMIR) or cell-mediated immune responses (CMIR) based on estimated breeding values. It was hypothesized that H-AMIR and H-CMIR cows produce colostrum (first milking) and milk (d 5 postcalving) with higher concentrations of IgG and $\beta$-LG. Data for IgG and $\beta-\mathrm{LG}$ in colostrum and milk were analyzed independently using mixed linear models. Least squares means were compared using Tukey's test. Cows classified as H-AMIR had higher IgG and $\beta$-LG concentrations in colostrum compared with A- and L-AMIR cows; $84 \%$ of H-AMIR, $69 \%$ of A-AMIR, and $68 \%$ of L-AMIR cows had over $5,000 \mathrm{mg} / \mathrm{dL}$ IgG in colostrum. No differences in $\operatorname{IgG}$ and $\beta-\mathrm{LG}$ concentrations in colostrum were noted among cows ranked on CMIR or in milk of cows ranked on AMIR. $\beta$-Lactoglobulin and IgG concentrations were positively correlated in colostrum. Breeding cows for H-AMIR status may reduce failure of passive transfer of IgG in their calves; $\beta$-LG may play a role in bovine immune defenses. Colostrum from H-AMIR cows may serve as a more economical feedstock source for manufacturing natural health products.

Key words: immunoglobulin, $\beta$-lactoglobulin, immune response, colostrum quality

\section{Short Communication}

Optimal dairy cattle health is important for highquality milk production. Disease results in economic losses due to decreased milk quality, colostrum quality, and milk production, as well as increased labor and

Received April 13, 2015.

Accepted November 21, 2015.

${ }^{1}$ Corresponding author: bmallard@uoguelph.ca treatment costs and culling (Zwald et al., 2006). Disease also raises concerns regarding food safety, food quality, and animal welfare. One potential solution to improve dairy health is identifying, and selectively breeding for, high (H)-immune response cows (Wagter et al., 2000; Mallard et al., 2011; Thompson-Crispi et al., 2012a).

The high immune response (HIR) test identifies cattle with balanced and robust levels of cell-mediated (CMIR) and antibody-mediated (AMIR) immune responses compared with other cows within and across herds (Wagter et al., 2000; Hernández et al., 2005; Thompson-Crispi et al., 2013). High-immune response cows have a lower occurrence of mastitis, metritis, ketosis, and retained placenta (DeLaPaz, 2008; ThompsonCrispi et al., 2012a, 2013) compared with low (L) and average (A) responders. Both AMIR and CMIR are heritable (Thompson-Crispi et al., 2012b), suggesting that immune response traits are amenable to genetic selection.

Bovine colostrum and milk are rich sources of bioactive components important in animal and human health (Séverin and Wenshui, 2005), respectively. Total IgG (consisting of $\operatorname{IgG}_{1}, \operatorname{IgG}_{2}$, and $\operatorname{IgG}_{3}$ subisotypes) and $\beta-\mathrm{LG}$ were components of particular interest in our study. In bovine colostrum, immunoglobulins compose greater than $95 \%$ of total whey protein, with $\operatorname{IgG}_{1}$ accounting for approximately $80 \%$ of the immunoglobulins (Butler, 1983). Adequate colostral quality has been defined as having IgG concentrations over $5,000 \mathrm{mg} / \mathrm{dL}$ and is associated with enhanced calf health (Weaver et al., 2000). The mean concentration of IgG in colostrum from Holstein dairy cows is reported to be less than one-half that for beef breeds, probably due to the higher volume of secretion produced by dairy cows (Guy et al., 1994). The 2007 US National Animal Health Monitoring System (NAHMS) report estimated that $19 \%$ of dairy heifer calves had inadequate serum concentrations of IgG (failure of passive transfer; NAHMS 2007).

In bovine milk, whey protein is approximately $50 \%$ $\beta$-LG (Hambling et al., 1992). The primary function 
of $\beta$-LG remains unclear, but it may function in transporting hydrophobic molecules (fatty acids, vitamin A, and vitamin D; Pérez and Calvo, 1995) and in absorption and metabolism of fatty acids (Kushibiki et al., 2001). $\beta$-Lactoglobulin has antibacterial activity against the mastitis-causing pathogens, Staphylococcus aureus and Streptococcus uberis (Chaneton et al., 2011), and fragments of $\beta-\mathrm{LG}$ generated by trypsin hydrolysis are bactericidal to gram-positive organisms (Pellegrini et al., 2001). Furthermore, $\beta-\mathrm{LG}$ has antiviral (Neurath et al., 1997), anticancer (Nakajima et al., 1997), and antioxidant (Elias et al., 2005) activities.

Because HIR cows (particularly cows classified as HAMIR) have decreased incidence rates and severity of clinical mastitis (Thompson-Crispi et al., 2013), and because bovine IgG and $\beta$-LG exert antibacterial activities against mastitis-causing pathogens (e.g., Escherichia coli, Staph. aureus; Butler, 1983), we hypothesized that HIR cows have increased concentrations of $\mathrm{IgG}$ and $\beta-\mathrm{LG}$ in colostrum and milk compared with cows with other immune response phenotypes. The objective of our study was, thus, to evaluate IgG and $\beta-\mathrm{LG}$ concentrations in colostrum and early lactation milk from $\mathrm{H}-, \mathrm{A}-$, and L-immune response cows using radial immunodiffusion and an ELISA, respectively.

Holstein cattle from the University of Guelph research herd (Elora, ON, Canada; approximately 300 cows) and a commercial herd (Drayton, ON, Canada; approximately 350 cows) were classified for AMIR and CMIR using a standardized 15-d protocol (Hine et al. 2011). Briefly, animals were immunized i.m. with type1 and type-2 test antigens. Blood samples were taken on $\mathrm{d} 0$ and 14 to evaluate primary IgG AMIR responses to the type- 2 test antigen by ELISA (using mouse monoclonal antibody anti-bovine IgG, clone BG-18, Sigma-Aldrich, Oakville, ON, Canada). A delayed-type hypersensitivity test to the type-1 antigen was initiated at d 14 (Thompson-Crispi et al. 2012b) and evaluated $24 \mathrm{~h}$ later to evaluate CMIR responses.

Immune response phenotypes in the research herd were evaluated (once per animal) over a 4-yr period, with data available on 390 animals. Full pedigree files, including 16,763 related animals, were provided by the Canadian Dairy Network (CDN, Guelph, ON, Canada). Both CMIR and AMIR were analyzed using univariate linear models as follows:

$$
y_{i j k l m}=\mu+\alpha \times d_{i}+\beta \times a_{j}+p_{k}+g_{l}+c_{m}+e_{i j k l m},
$$

where $y_{i j k l m}=$ AMIR or CMIR; $\mu=$ overall mean; $d_{i}=$ d 0 data for AMIR or control site for CMIR; $a_{j}=$ age in months at immune response test; $\alpha$ and $\beta$ are regression coefficients; $p_{k}=$ pregnancy status (not pregnant,
$1-100$, or $101-200 \mathrm{~d}$ in calf); $g_{l}=$ immune response test group (year of testing); $c_{m}=$ random effect of animal; and $e_{i j k l m}=$ residual error. Heritabilities of 0.29 for AMIR and 0.19 for CMIR were estimated previously (Thompson-Crispi et al. 2012b).

The commercial herd was phenotyped using different parameters than the research herd. Animals were categorized into 7 groups: bred heifers, cows being bred, calves, dry cows, high grain, low grain, and transition cows. Data were available for 265 animals. Full pedigree files, including 15,449 related animals, were provided by CDN. Both CMIR and AMIR were analyzed using univariate linear models as follows:

$$
y_{i j k l}=\mu+\alpha \times d_{i}+g l_{j}+g p_{k}+c_{l}+e_{i j k l},
$$

where $y_{i j k l}=$ AMIR or CMIR; $\mu=$ overall mean; $d_{i}$ $=\mathrm{d} 0$ data for AMIR or control site for CMIR; $\alpha$ is a regression coefficient; $g l_{j}=$ group of animals nested into lactation effect (lactation $0,1,2,3$, and $\geq 4$ ); $g p_{k}$ $=$ group of animals nested into pregnancy status effect (not pregnant, 1-100, or 101-200, >200 d in calf); $c_{l}$ $=$ random effect of animal; and $e_{i j k l}=$ residual error. Heritabilities of 0.29 for AMIR and 0.19 for CMIR were used as above.

Breeding values were estimated for the 2 herds separately. The genetic analysis was performed with ASReml software (Gilmour et al., 1995). Cattle were ranked as $\mathrm{H}$ or $\mathrm{L}$ if $\mathrm{EBV}$ were greater than 1 standard deviation above or more than 1 standard deviation below the mean response for each trait, respectively. Average AMIR and CMIR cows had EBV within 1 standard deviation of the mean.

Colostrum and milk samples from a total of 88 cows from the research herd were tested, including 21, 45, and $22 \mathrm{H}, \mathrm{A}$, and L responders, respectively, for AMIR and 15,58 , and $15 \mathrm{H}, \mathrm{A}$, and $\mathrm{L}$ responders, respectively, for CMIR. For the commercial herd, a total of 20 cows were tested, including 4,10 , and $6 \mathrm{H}, \mathrm{A}$, and $\mathrm{L}$ responders, respectively, for AMIR and 4, 11, and $5 \mathrm{H}, \mathrm{A}$, and $\mathrm{L}$ responders, respectively, for CMIR. The d-5 milk geometric mean SCC for cows being researched and commercial herds were 123,046 and 256,112 cells/mL, respectively, with a geometric mean SCC of 141,869 cells/mL for all the cows in the study.

Composite samples were collected on d 0 (day of calving, colostrum) and 5 (milk). Samples were defatted by centrifugation $(11,000 \times g, 30 \mathrm{~min}$ at room temperature) and stored at $-80^{\circ} \mathrm{C}$.

Radial immunodiffusion (Mancini et al., 1965) was used to determine total IgG concentrations using commercially prepared plates (Triple J Farms, Bellingham, WA). The IgG standards (196, 1,402, and 2,748 mg/ 
$\mathrm{dL}$ ) for colostrum and $(10,50,100 \mathrm{mg} / \mathrm{dL})$ for milk, provided by the manufacturer were used to generate standard curves. Precipitate zone diameter was measured $17 \mathrm{~h}$ after loading of each plate. Samples were diluted in PBS and run at dilutions of 1:4 and undiluted for colostrum and milk samples, respectively. If the diameter of the zone of precipitation was greater than that of the most concentrated standard, the sample was diluted further and rerun. The intraplate coefficient of variation for the radial immunodiffusion was $1.4 \%$ and the interplate variation was $4.3 \%$.

$\beta$-Lactoglobulin was assayed using an ELISA kit (Bethyl Laboratories, Montgomery, TX). MaxiSorp 96-well plates (Fisher Scientific, Waltham, MA) were coated with affinity purified rabbit anti-bovine $\beta$-LG antibody diluted 1:100 in coating buffer $(0.05 \mathrm{M}$ carbonate-bicarbonate, $\mathrm{pH}=9.6$; Fisher Scientific) at 100 $\mu \mathrm{L} /$ well and incubated at room temperature (RT) for $1 \mathrm{~h}$. Plates were washed using wash buffer (WB, 50 $\mathrm{m} M$ Tris, $0.14 M \mathrm{NaCl}$, and $0.05 \%$ Tween $20, \mathrm{pH}=$ 8.0; Sigma-Aldrich). Plates were blocked with $200 \mu \mathrm{L} /$ well of WB and incubated at RT for $30 \mathrm{~min}$. Diluted standard or sample was added at $100 \mu \mathrm{L} /$ well in duplicate and incubated at RT for $1 \mathrm{~h}$. Standards were diluted in a 2-fold dilution series to generate a standard curve. Colostrum and milk samples were diluted in a 4-fold dilution series in WB. Plates were washed and $100 \mu \mathrm{L} /$ well of horseradish peroxidase-conjugated rabbit anti-bovine $\beta$-LG antibody diluted 1:100,000 in WB was added. Plates were incubated at RT for $1 \mathrm{~h}$ before washing. Enzyme substrate (tetramethylbenzidine, Fisher Scientific) was added at $100 \mu \mathrm{L} /$ well for 8 min; stop solution (0.18 $M \mathrm{H}_{2} \mathrm{SO}_{4}$, Fisher Scientific) was subsequently added $(100 \mu \mathrm{L} /$ well $)$. Optical density was measured at $450 \mathrm{~nm}$ using a BioTek (Winooski, VT) plate reader. The intraplate coefficient of variation for this assay was $3.2 \%$ and the interplate variation was $6.7 \%$.

Data for IgG and $\beta$-LG in colostrum and milk were analyzed independently using linear mixed models (PROC MIXED, SAS, Cary, NC). The statistical model was

$$
y_{i j k l}=\mu+p_{i}+w_{j}+b_{k}+i_{l}+e_{i j k l}
$$

where $y_{\mathrm{ijkl}}=\operatorname{IgG}$ or $\beta$-LG; $\mu=$ the overall mean; $p_{i}=$ parity $(1,2,3$ and $\geq 4) ; w_{j}=$ colostrum or milk weight $(\mathrm{kg})$ of complete composite milking; $b_{k}=$ herd (commercial or research); $i_{l}=$ immune response category $(\mathrm{H}$, $\mathrm{A}$, or L for AMIR and CMIR); and $e_{i j k l}=$ the residual error. Covariates with $P$-values $>0.10$ were removed from the model. Interactions were tested and removed if nonsignificant, preserving hierarchy. Normality was tested using the Shapiro-Wilk test; data that were not normally distributed were log-transformed. Least squares means were estimated and Tukey's test was used to compare immune response groups. A Pearson correlation coefficient was used to determine associations between IgG and $\beta-\mathrm{LG}$ in colostrum and milk.

Concentrations of IgG in colostrum ranged from 399 to $20,864 \mathrm{mg} / \mathrm{dL},($ mean $=7,048 \mathrm{mg} / \mathrm{dL}, \mathrm{SD}=3,556)$. The IgG in milk ranged from 19 to $2,096 \mathrm{mg} / \mathrm{dL}$ (mean $=90 \mathrm{mg} / \mathrm{dL}, \mathrm{SD}=216)$. $\beta$-Lactoglobulin concentrations in colostrum ranged from 2.5 to $12 \mathrm{mg} / \mathrm{mL}$ (mean $=6.6 \mathrm{mg} / \mathrm{mL}, \mathrm{SD}=2.0) ; \beta-\mathrm{LG}$ in milk ranged from 0.2 to $4.2 \mathrm{mg} / \mathrm{mL}($ mean $=1.3 \mathrm{mg} / \mathrm{mL}, \mathrm{SD}=0.89)$.

Colostrum samples for 78 cows out of 108 (72\%) contained more than the suggested minimum of $5,000 \mathrm{mg} /$ dL of IgG (Weaver et al., 2000). Twenty-one out of 25 (84\%) of H-AMIR, 38 out of $55(69 \%)$ of A-AMIR, and 19 out of $28(68 \%)$ of L-AMIR cows had over $5,000 \mathrm{mg} /$ dL of IgG in their colostrum. Fourteen out of $19(74 \%)$ H-CMIR, 49 out of 69 (71\%) A-CMIR and 15 out of 20 (75\%) L-CMIR had over $5,000 \mathrm{mg} / \mathrm{dL}$ of IgG in their colostrum.

Parity 2 cows had significantly lower IgG concentrations in colostrum compared with parity 1,3 , and $\geq 4$ cows (Figure 1A). In contrast, parity 1 cows had significantly lower $\beta$-LG concentrations in milk compared with parity 2 and 3 cows (Figure 1B).

The trait AMIR was found to have a significant $(P<$ 0.01 ) effect on colostral IgG and $\beta$-LG concentrations, with H-AMIR cows having significantly more $\operatorname{IgG}$ and $\beta$-LG in colostrum compared with A- and L-AMIR cows. The H-AMIR cows had 2,472 and 1,599 mg/dL higher concentrations of $\mathrm{IgG}$ in colostrum on average than cows with A- and L-AMIR, respectively (Figure 2 ). This result is not surprising, because H-AMIR cows were classified as having higher serum IgG antibody responses to a type- 2 antigen. The $\mathrm{IgG}_{1}$ in cattle is considered characteristic of type- 2 responses, and $\mathrm{IgG}_{1}$ constitutes the major immunoglobulin component in bovine colostrum (Butler, 1983). The H-AMIR cows also had 1.8 and $1.6 \mathrm{mg} / \mathrm{mL}$ higher concentrations of $\beta$-LG in colostrum compared with A-and L-AMIR cows, respectively (Figure 3). No significant differences in colostral IgG and $\beta$-LG concentrations were found among cows classified based on CMIR. In vitro studies suggest that in cattle production of antibodies of the $\mathrm{IgG}_{2}$ isotype is stimulated by $\mathrm{IFN} \gamma$, a cytokine associated with Th1-type responses (Estes and Brown, 2002). The similarity of (total) IgG concentrations in colostrum from $\mathrm{H}-, \mathrm{A}-$, and L-CMIR cows is consistent with these in vitro findings, as $\mathrm{IgG}_{2}$ is not transferred efficiently from serum into colostrum (Butler, 1983). No significant differences in milk IgG concentrations 
A

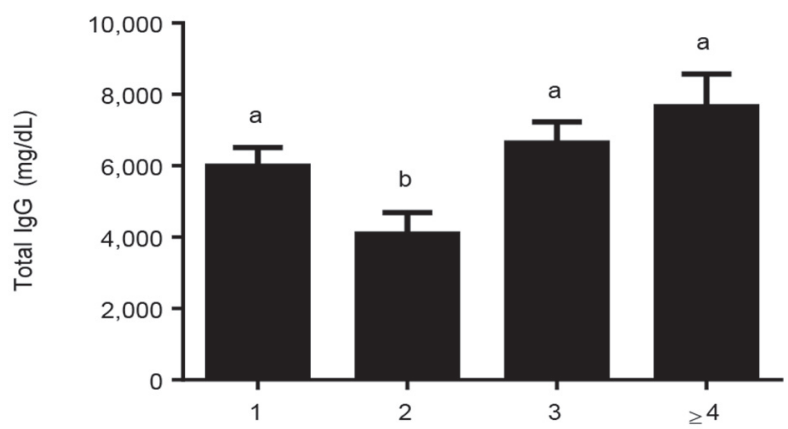

B

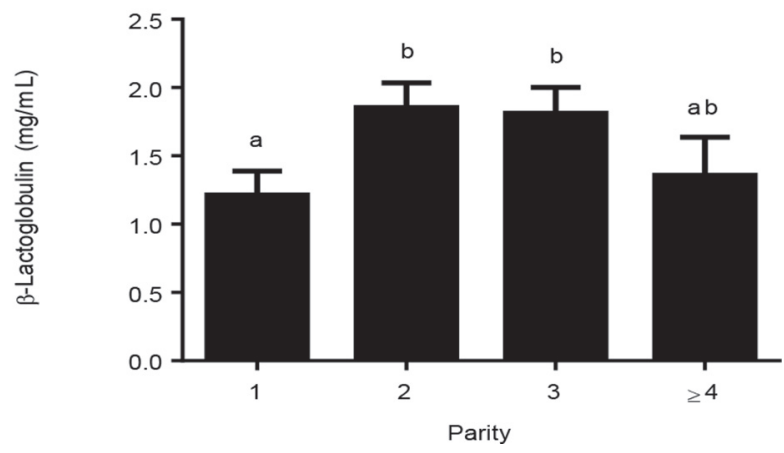

Figure 1. (A) Total $\mathrm{IgG}(\mathrm{mg} / \mathrm{dL})$ concentrations in colostrum based on parities of $1(\mathrm{n}=43), 2(\mathrm{n}=28), 3(\mathrm{n}=27)$, and $\geq 4(\mathrm{n}=$ $10) ; \mathrm{n}=108$. (B) $\beta$-Lactoglobulin $(\mathrm{mg} / \mathrm{mL})$ concentrations in milk based on parity $1(\mathrm{n}=42), 2(\mathrm{n}=27), 3(\mathrm{n}=25)$, and $\geq 4(\mathrm{n}=9)$; $\mathrm{n}=103$. Columns represent LSM with bars indicating SEM. Columns with different letters $(\mathrm{a}, \mathrm{b})$ differ significantly $(P<0.05)$.

were noted among cows classified according to AMIR or CMIR. Although IgG concentrations were not higher in H-AMIR cows, it has been demonstrated previously that, following vaccination, $\mathrm{H}$-AMIR cows secrete higher titers of antibodies in milk compared with A- and L-AMIR cows (Wagter et al., 2000).

Immunoglobulin $\mathrm{G}$ concentrations in colostrum and milk were negatively correlated $(\mathrm{r}=-0.23, P=0.02)$. Immunoglobulin $\mathrm{G}$ and $\beta$-LG concentrations in colostrum were positively correlated $(\mathrm{r}=0.48, P<0.001)$, and colostrum and milk yield were positively correlated $(\mathrm{r}=0.33, P<0.001)$. Similar to the findings of Guidry et al. (1980), milk weight was negatively correlated $(\mathrm{r}$ $=-0.20, P=0.04$ ) with $\operatorname{IgG}$ concentration in milk; thus, lower concentrations of $\operatorname{IgG}$ occurred in larger milk volumes.

It is notable that the research herd had significantly higher concentrations of $\operatorname{IgG}$ and $\beta-\mathrm{LG}$ in colostrum and significantly lower IgG and $\beta$-LG in milk compared with the commercial herd (data not shown). Exposure to different pathogen loads may stimulate the immune response to various degrees, but mean SCC on d 5 postcalving were higher in the commercial herd, and

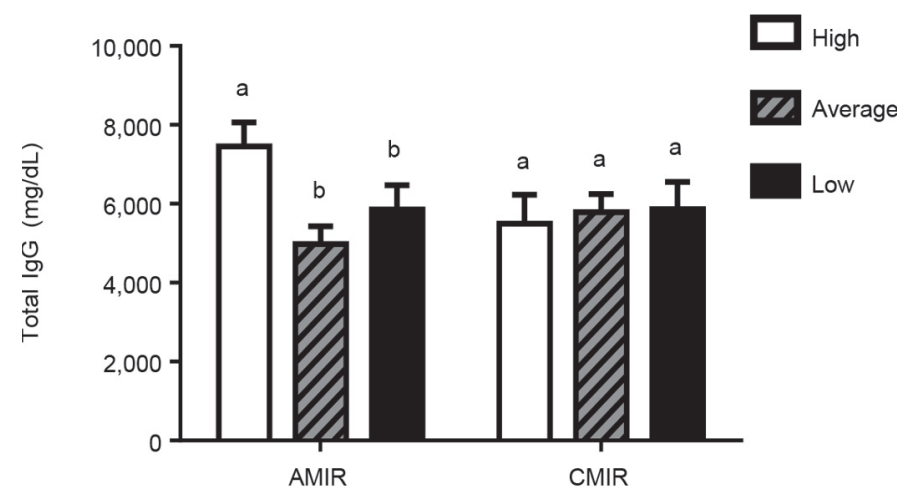

Im mune Response

Figure 2. Total IgG $(\mathrm{mg} / \mathrm{dL})$ concentrations in colostrum (first milk postcalving) from high $(\mathrm{n}=25)$, average $(\mathrm{n}=55)$, and low $(\mathrm{n}=$ 28 ) cows ranked for antibody-mediated immune response (AMIR) and from high $(\mathrm{n}=19)$, average $(\mathrm{n}=69)$, and low $(\mathrm{n}=20)$ cows ranked for cell-mediated immune response (CMIR). Columns represent LSM with bars indicating SEM. Within an immune response trait, columns with different letters $(\mathrm{a}, \mathrm{b})$ differ significantly $(P<0.05)$.

SCC were not significant covariates in the statistical models. Maunsell et al. (1998) compared SCC, colostral volumes, and $\operatorname{IgG}_{1}$ concentrations in colostrum from infected and noninfected mammary glands of Holstein cows. Infection of the mammary gland was associated with higher SCC in colostrum and lower volumes of colostrum, but concentrations of IgG in colostrum did not differ from those in noninfected glands. This suggests that differences in $\operatorname{IgG}$ concentrations observed among cows in the 2 herds in the present study are unlikely to be due to any differences in prevalence of mastitis between the herds.

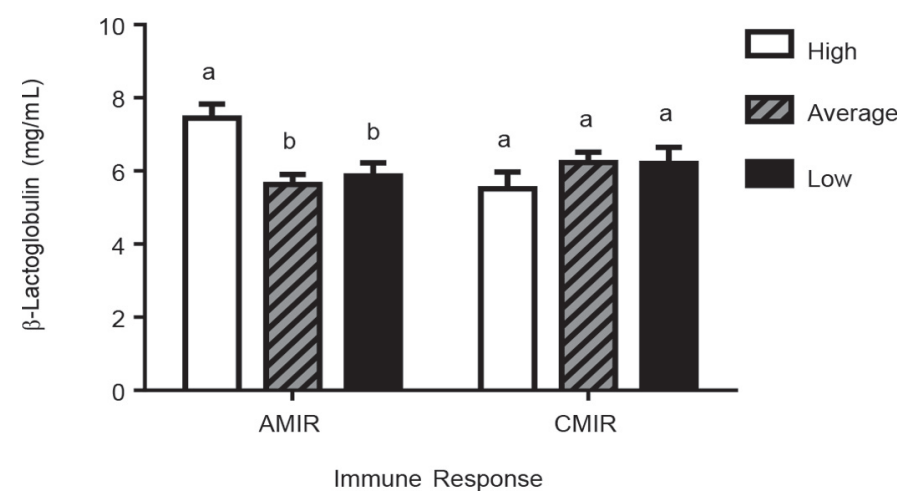

Figure 3. $\beta$-Lactoglobulin $(\mathrm{mg} / \mathrm{mL})$ concentrations in colostrum (first milk postcalving) for high $(\mathrm{n}=25)$, average $(\mathrm{n}=55)$, and low $(\mathrm{n}$ $=28$ ) cows ranked for antibody-mediated immune response (AMIR) and for high $(\mathrm{n}=19)$, average $(\mathrm{n}=69)$, and low $(\mathrm{n}=20)$ cows ranked for the cell-mediated immune response (CMIR). Columns represent LSM with bars indicating SEM. Within an immune response trait, columns with different letters $(\mathrm{a}, \mathrm{b})$ differ significantly $(P<0.05)$. 
Higher IgG concentrations were present in colostrum of higher-parity cows. Because H-AMIR status has been associated with longevity (Thompson-Crispi, 2012), breeding for H-AMIR may lead to additional gains in IgG in colostrum associated with longer herd life.

A stable proportion of $\beta$-LG may suggest an important function for the protein in colostrum. The primary function of $\beta-\mathrm{LG}$ is unclear. In our study, H-AMIR cows produced colostrum containing higher concentrations of both IgG and $\beta$-LG. Based on H-AMIR cows having more colostral IgG and $\beta$-LG, and because $\operatorname{IgG}$ primarily functions as an immune response molecule, it is hypothesized that $\beta$-LG also contributes to immune system function.

In our study, colostrum from H-AMIR cattle had higher concentrations of IgG on average compared with A- or L-AMIR cows. Acceptable colostrum quality has been defined as having concentrations of IgG over 5,000 $\mathrm{mg} / \mathrm{dL}$. Failure of passive transfer (calf serum IgG $<1,000 \mathrm{mg} / \mathrm{dL}$ at $24-48 \mathrm{~h}$ of age, Weaver et al., 2000) occurs when calves receive inadequate quantities of colostral IgG or ingest colostrum too late after birth, and is associated with an increased incidence of alimentary and respiratory tract infections, as well as death within the first weeks of life. Eighty-four percent of H-AMIR cows produced colostrum containing greater than 5,000 $\mathrm{mg} / \mathrm{dL}$ of IgG per deciliter compared with $69 \%$ of AAMIR and $68 \%$ of L-AMIR cows. These results suggest that feeding calves colostrum from H-AMIR cows can reduce the incidence of failure of passive transfer in calves. In situations where H-AMIR cows produce more colostrum than needed for their own calf, excess colostrum could be used to benefit additional calves. Moreover, the lack of high-quality colostrum in many farms could be improved by increasing the percentage of H-AMIR cows in the herd.

The health benefits of whey proteins are under investigation in humans, with supplements manufactured from by-products of cheesemaking. Colostrum from H-AMIR cows may provide a more efficient source of ingredients for future manufacturing of natural health products for human consumption. Future research is required to determine if $\beta$-LG plays a role in preventing septicemia, diarrhea, and respiratory infections in calves after birth and if this molecule could be used to compensate for lack of protective immunoglobulins in colostrum.

Quantifying total IgG and $\beta$-LG in colostrum and milk from cows with different adaptive immune response phenotypes was the focus of our study. The H-AMIR cows had significantly greater concentrations of IgG and $\beta$-LG in colostrum compared with A- and L-AMIR cows. The H-AMIR cows were also the most likely to exceed the recommended minimum concen- tration of $\operatorname{IgG}$ in colostrum. Ultimately, breeding for cattle with H-AMIR may lead to the production of better quality colostrum to improve passive protection in young calves.

\section{ACKNOWLEDGMENTS}

This research was funded by the Natural Sciences and Engineering Research Council of Canada (NSERC, Ottawa, ON, Canada), and the Ontario Ministry of Agriculture and Food and Rural Affairs (OMAFRA, Guelph, ON, Canada). The authors thank the staff of the Elora Dairy Research station (Elora, ON, Canada), and Terri Ollivett (University of Guelph, Guelph, ON, Canada) and students for assistance in collection of samples.

\section{REFERENCES}

Butler, J. E. 1983. Bovine immunoglobulins: An augmented review. Vet. Immunol. Immunopathol. 4:43-152.

Chaneton, L., J. Pérez Sáez, and L. Bussmann. 2011. Anti-microbial activity of bovine $\beta$-lactoglobulin against mastitis-causing bacteria. J. Dairy Sci. 94:138-145.

DeLaPaz, J. 2008. Using humoral and cellular response to novel antigens in periparturent dairy cows as a measure of genetic disease resistance in dairy cows. MSc. thesis. University of Florida, Gainesville. http://etd.fcla.edu/UF/UFE0022360/delapaz_j.pdf.

Elias, R. J., D. J. McClements, and E. A. Decker. 2005. Anti-oxidant activity of cysteine, tryptophan, and methionine residues in continuous phase $\beta$-lactoglobulin in oil-in-water emulsions. J. Agric. Food Chem. 53:10248-10253.

Estes, D. M., and W. C. Brown. 2002. Type 1 and type 2 responses in regulation of Ig isotype expression in cattle. Vet. Immunol. Immunopathol. 90:1-10.

Gilmour, A. R., R. Thompson, and B. R. Cullis. 1995. Average Information REML, an efficient algorithm for variance parameter estimation in linear mixed models. Biometrics 51:1440-1450.

Guidry, J., J. E. Butler, R. E. Pearson, and B. T. Weinland. 1980. IgA, IgG1, IgG2, IgM, and BSA in serum and mammary secretion throughout lactation. Vet. Immunol. Immunopathol. 1:329-341.

Guy, M. A., T. B. McFadden, D. C. Cockrell, and T. E. Besser. 1994. Regulation of colostrum formation in beef and dairy cows. J. Dairy Sci. 77:3002-3007.

Hambling, S. G., A. S. McAlpine, and L. Sawyer. 1992. $\beta$-Lactoglobulin. Pages 141-190 in Advanced Dairy Chemistry-1: Proteins. Elsevier Applied Science, London, UK.

Hernández, A., J. A. Yager, B. N. Wilkie, K. E. Leslie, and B. A. Mallard. 2005. Evaluation of bovine cutaneous delayed-type hypersensitivity (DTH) to various test antigens and a mitogen using several adjuvants. Vet. Immunol. Immunopathol. 104:45-58.

Hine, B. C., S. Cartwright, and B. Mallard. 2011. Effect of age and pregnancy status on adaptive immune responses of Canadian Holstein replacement heifers. J. Dairy Sci. 94:981-991.

Kushibiki, S., K. Hodate, J. Kurisaki, H. Shingu, Y. Ueda, A. Watanabe, and M. Shinoda. 2001. Effect of $\beta$-lactoglobulin on plasma retinol and triglyceride concentrations, and fatty acid composition in calves. J. Dairy Res. 68:579-586.

Mallard, B. A., H. Atalla, S. Cartwright, B. C. Hine, B. Hussey, M. Paibomesai, K. A. Thompson-Crispi, and L. Wagter-Lesperance. 2011. Genetic and epigenetic regulation of the bovine immune system: Practical implications of high immune response technology. Pages 53-63 in Proc. National Mastitis Council 50th Annu. Mtg. National Mastitis Council, New Prague, MN. 
Mancini, G., A. Carbonara, and J. Heremans. 1965. Immunochemical quantitation of antigens by single radial immunodiffusion. Immunochemistry $2: 235-254$.

Maunsell, F. P., D. E. Morin, P. D. Constable, W. L. Hurley, G. C. McCoy, I. Kakoma, and R. E. Isaacson. 1998. Effects of mastitis on the volume and composition of colostrum produced by Holstein cows. J. Dairy Sci. 81:1291-1299.

NAHMS (National Animal Health Monitoring System). 2007. Dairy 2007. Heifer Calf Health and Management Practices on U.S. Dairy Operations, 2007. Accessed Aug. 24, 2015. http://www.aphis.usda. gov/animal_health/nahms/dairy/downloads/dairy07/Dairy07_ ir_CalfHealth.pdf.

Nakajima, M., I. Shinoda, T. Mikogami, H. Iwamoto, S. I. Hashimoto, H. Miyauchi, Y. Fukuwatari, and H. Hayasawa. 1997. $\beta$-Lactoglobulin suppresses melanogenesis in cultured human melanocytes. Pigment Cell Res. 10:410-413.

Neurath, A., A. Debnath, N. Strick, Y. Y. Li, K. Lin, and S. Jiang. 1997. 3-hydroxyphthaloyl-3-lactoglobulin. II. Anti-human immunodeficiency virus type 1 activity in in vitro environments relevant to prevention of sexual transmission of the virus. Antivir. Chem. Chemother. 8:141-148.

Pellegrini, A., C. Dettling, U. Thomas, and P. Hunziker. 2001. Isolation and characterization of four bactericidal domains in the bovine $\beta$-lactoglobulin. Biochim. Biophys. Acta 1526:131-140.

Pérez, M. D., and M. Calvo. 1995. Interaction of $\beta$-lactoglobulin with retinol and fatty acids and its role as a possible biological function for this protein: A review. J. Dairy Sci. 78:978-988.
Séverin, S., and X. Wenshui. 2005. Milk biologically active components as nutraceuticals: Review. Crit. Rev. Food Sci. Nutr. 45:645-656.

Thompson-Crispi, K. A., B. Hine, M. Quinton, F. Miglior, and B. Mallard. 2012a. Association of disease incidence and adaptive immune response in Holstein dairy cows. J. Dairy Sci. 95:3888-3893.

Thompson-Crispi, K. A. 2012. Genetic regulation of immune responses in Holstein dairy cows across Canada. PhD thesis. University of Guelph, Guelph, ON, Canada. http://hdl.handle.net/10214/3915.

Thompson-Crispi, K. A., F. Miglior, and B. A. Mallard. 2013. Incidence rates of clinical mastitis among Canadian Holsteins classified as high, average, or low immune responders. Clin. Vaccine Immunol. 20:106-112.

Thompson-Crispi, K. A., A. Sewalem, F. Miglior, and B. A. Mallard. 2012b. Genetic parameters of immune response traits in Canadian Holsteins. J. Dairy Sci. 95:401-409.

Wagter, L. C., B. A. Mallard, B. N. Wilkie, K. E. Leslie, P. J. Boettcher, and J. C. M. Dekkers. 2000. A quantitative approach to classifying Holstein cows based on antibody responsiveness and its relationship to peripartum mastitis occurrence. J. Dairy Sci. $83: 488-498$

Weaver, D. M., J. W. Tyler, D. C. VanMetre, D. E. Hostetler, and G. M. Barrington. 2000. Passive transfer of colostral immunoglobulins in calves. J. Vet. Intern. Med. 14:569-577.

Zwald, N. R., K. A. Weigel, Y. M. Chang, R. D. Welper, and J. S. Clay. 2006. Genetic analysis of mastitis data from on farm management software using threshold models. J. Dairy Sci. 89:330-336. 